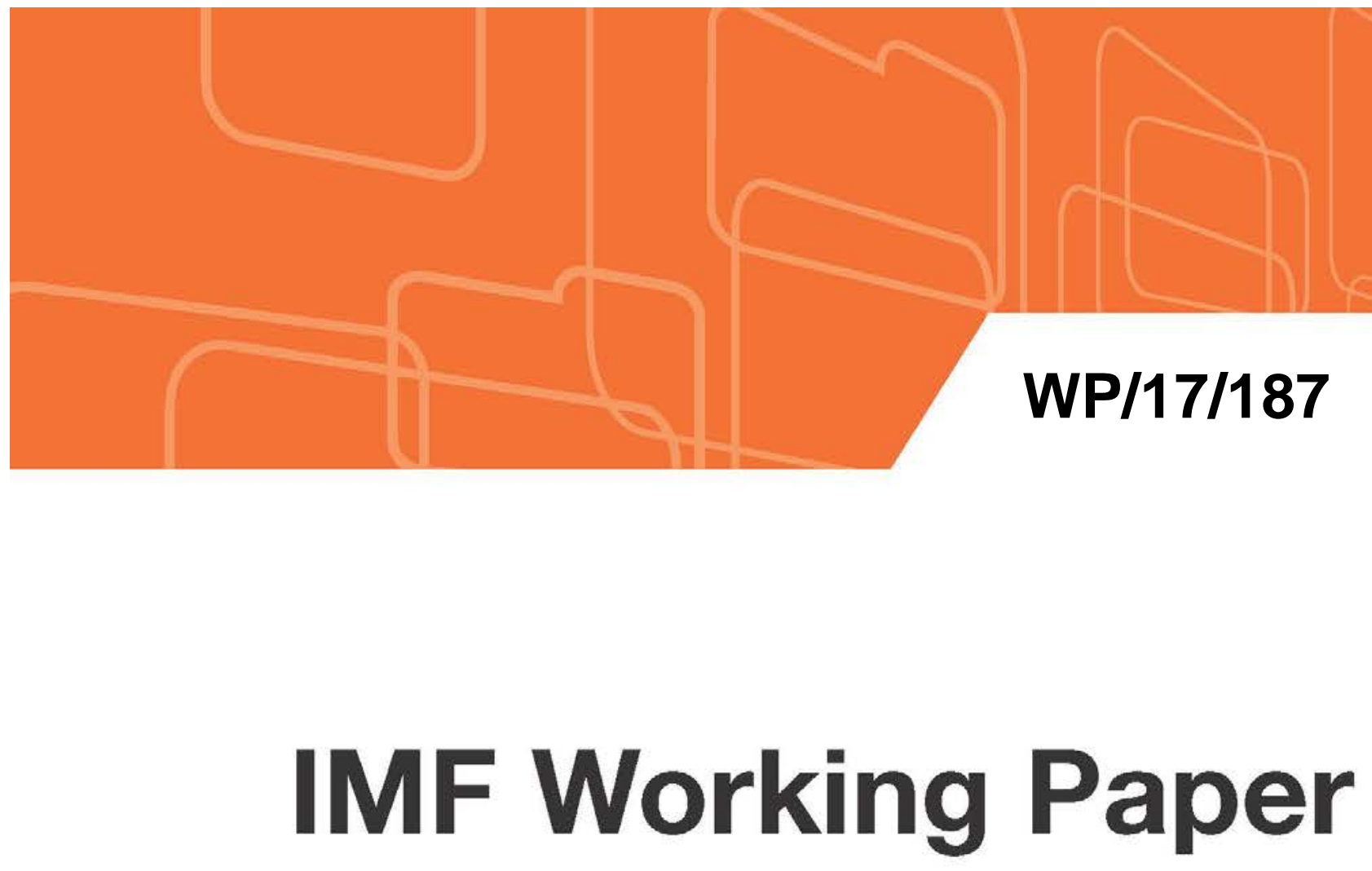

\title{
Taxation and the Peer-to-Peer Economy
}

by Aqib Aslam and Alpa Shah

IMF Working Papers describe research in progress by the author(s) and are published to elicit comments and to encourage debate. The views expressed in IMF Working Papers are those of the author(s) and do not necessarily represent the views of the IMF, its Executive Board, or IMF management.

$$
\text { I N T E R N A T I O N A L M O N E T A R Y F U N D }
$$




\title{
IMF Working Paper
}

Fiscal Affairs Department

Taxation and the Peer-to-Peer Economy ${ }^{1}$

Prepared by Aqib Aslam and Alpa Shah²

Authorized for distribution by Ruud De Mooij

August 2017

\section{IMF Working Papers describe research in progress by the author(s) and are published to elicit comments and to encourage debate. The views expressed in IMF Working Papers are those of the author(s) and do not necessarily represent the views of the IMF, its Executive Board, or IMF management.}

\begin{abstract}
The growth of the peer-to-peer (P2P) economy over the last decade has captivated both stock markets and policymakers alike. While the means for transacting might be different to existing firm structures - with the emergence of digital platforms that connect individual buyers and sellers directly - the tax behavior of individuals operating in this new economy are very familiar. What is clear is that while the P2P economy has potentially exacerbated existing policy, administrative, and revenue-mobilization challenges associated with small business taxation-such as the choice of the tax base and how to set tax thresholds-, the technology behind P2P platforms presents a valuable opportunity to eventually solve them.
\end{abstract}

JEL Classification Numbers: D23, D47, H2, L1.

Keywords: Digital platforms, direct tax, indirect tax, peer-to-peer markets, tax compliance, transaction costs.

Author’s E-Mail Address: aaslam@imf.org; ashah@imf.org

\footnotetext{
${ }^{1}$ This paper also appears as: Aslam, Aqib, and Alpa Shah. 2017. “Taxation and the Peer-to-Peer Economy”, in Gupta, Sanjeev, Michael Keen, Alpa Shah, and Genevieve Verdier (Eds.), Digital Revolutions in Public Finance, Washington D.C.: International Monetary Fund.

2 The authors would like to thank Beth Adair, Chelsea Barabas, Sonia Carrera, Francois Chadwick, Peter Coles, Ruud De Mooij, Johannes Degn, Raphael Espinoza, Peter Gigante, Sanjeev Gupta, Jonathan Hall, Zach Jones, Michael Keen, Patrick Kallerman, Jed Kolko, Pooja Kondabolu, Jonathan Lieber, Idan Netser, Igor Popov, Lucas Puente, Jennifer Rowland, Joshua Sandler, Mick Thackray, Robert Trotter, Genevieve Verdier, and Travis Woodward for useful comments and discussions and John Damstra for excellent research assistance. All remaining errors are our own.
} 


\section{Contents}

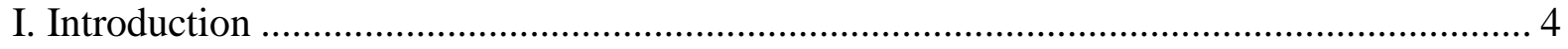

II. The Peer-to-Peer Economy ……………………….................................................... 5

A. The Scale of the Peer-to-Peer Economy …………………………………………..... 7

B. Some Theory and Empirics on the Peer-to-Peer Economy …………………………....... 9

Shrinking Transaction Costs ........................................................................................ 9

A Short Primer on Two-sided Markets .......................................................................... 10

Some Empirical Results from the Literature …………………………....................... 12

III. Key Tax-Relevant Features of the Peer-to-Peer Economy …….......................................... 14

A. Growth and Classification of P2P Activities ............................................................ 14

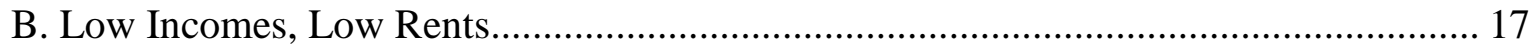

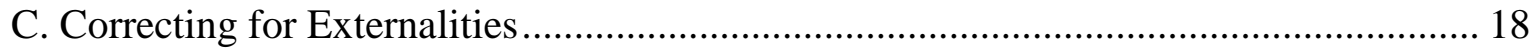

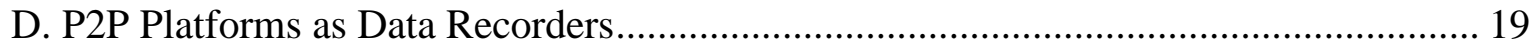

IV. How Should We Tax the Peer-to-Peer Economy? ............................................................ 19

A. A Neutral or Targeted Treatment of P2P Businesses .................................................... 20

B. Tax Thresholds .................................................................................................... 21

C. Cross-Border Taxation of P2P Services .................................................................... 22

D. Treatment of Capital and Labor ................................................................................. 23

E. A Presumptive Tax System for the P2P Economy …………………………………... 24

F. Exploiting Technology to Improve Tax Administration .............................................. 26

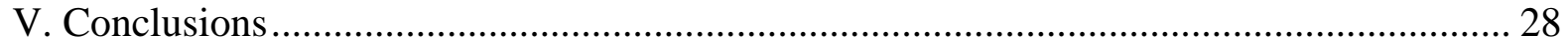

Box 1. The Peer-to-Peer Economy in Developing Economies................................................ 30

Box 2. Current Tax Treatment of P2P Businesses................................................................ 31 


\section{INTRODUCTION}

As the digital, peer-to-peer (P2P) economy takes off worldwide, it has come under increasing scrutiny and criticism amid the perception that it is far less regulated and taxed than other types of business. ${ }^{3}$ Some view this light government touch as distorting competition and giving individuals and businesses in the $\mathrm{P} 2 \mathrm{P}$ economy an unfair advantage over competing businesses in the same sectors. Others argue that, by putting beneficial pressure on restrictive practices, it is enhancing efficiency.

If P2P economy users are indeed subject to lower taxation-because of preferential rates or simply underreporting of income-government tax revenues may be at risk, especially if other more tax-rich activities are being displaced. At the same time, it is possible that this new way of doing business is formalizing activities in certain sectors, bringing them within reach of the regulatory and tax authorities.

That the definition and reach of the P2P economy remains open for debate compounds the controversy. Many terms have been coined to describe new digital P2P activities, for example, the "sharing economy" and the "gig economy". ${ }^{4}$ However, these names typically refer to only a subset of the transactions of interest, since P2P businesses can exist in any online market where transactions can be characterized by exchange (sale) or rental (sharing) between two parties—often individuals.

Importantly, the P2P model - the transaction of goods and services between individual buyers and sellers - is not a new way of conducting business (think of bartering). What distinguishes it in recent years are the technological developments that have eliminated various transaction costs associated with running a business, allowing smaller-scale activity to proliferate and collectively challenge incumbent, larger-scale corporate businesses. P2P trading has therefore managed to penetrate an increasing range of sectors, with an increasing range of goods and services sectors boasting $\mathrm{P} 2 \mathrm{P}$ provision.

Certain sectors have borne the brunt of the criticism. For instance, the rapid ascension of $\mathrm{P} 2 \mathrm{P}$ platforms in the hospitality and tourism sectors has raised questions about whether these new entrants are somehow tax-advantaged compared with traditional businesses, violating the principle of tax neutrality. In the price-setting ride-sharing industry, the question of whether drivers are employees or self-employed has been another source of controversy. This

\footnotetext{
3 The term "P2P economy” encompasses P2P participants (buyers and sellers) and digital platforms, across all sectors, involved in P2P activities. "P2P businesses” and "P2P sellers" are used interchangeably to describe those entities on the supply side that are providing goods and services over P2P platforms.

4 “Gig economy” refers to activities centered around a specific job or task (a gig). While this terminology could suggest smaller-scale interactions in the marketplace, importantly larger corporations also use P2P infrastructure as a supplementary sales channel to reach a broader consumer base. This is often referred to as the business-to-peer channel.
} 
issue can have important implications for whom the burden of tax compliance falls on, as well as the level of social insurance and benefits payable.

Governments have become aware of the need to clarify tax obligations for users of the P2P economy with some already having issued specific guidance. They have also recognized the potential benefits of getting access to and using the large amount of information held by digital platforms for enhancing compliance. The role of the platform as a withholding agent has also been identified, raising questions of whether this is feasible for all taxes that P2P users are liable for. Therefore, with increasing numbers of participants and a growing number of markets in which the P2P business model can thrive, interest in the scale, scope, and taxation of the P2P economy is inevitable.

This paper seeks to address several questions. First and foremost, what are implications of the P2P economy for tax policy and administration? An important part of the answer rests on understanding whether the economic impact of the P2P economy and the P2P business model itself warrants special tax treatment. If the fundamental economic activity of these new businesses is different from existing sectors, are current tax policies sufficient to deal with them? If not, does the current tax structure allow for greater avoidance by participants in the P2P economy? And, if so, can the information which platforms accumulate help to improve compliance with minimal cost? More fundamentally, does the scale and nature of P2P activities suggest an alternative system of taxation — or even a simplification of existing taxes - to ensure that the government can share in the value being created? What this paper will highlight is that from a tax policy perspective the case for a separate or special tax treatment is not immediately obvious. What appears to be a tax administration issue could be mistaken for a tax policy issue.

The next section defines the P2P economy and reviews the literature on theory and empirics. The paper then explores features of the P2P economy relevant for tax policy and administration, and, finally, considers design in these two areas in a world where P2P activities are growing.

\section{The PEER-TO-PEER ECONOMY}

The P2P economy can be described as a collection of virtual marketplaces that connect individuals looking to trade goods and services with one another through digital platforms. On one side, you have the buyers, who want specific goods or services, and, on the other, the sellers that own the good to be sold (or rented) or control the assets needed to provide the service. Table 1 lists examples of P2P platforms in different sectors. 
Table 1. Examples of Peer-to-Peer Platforms Across Sectors.

\begin{tabular}{ll}
\hline \multicolumn{1}{c}{ Industry/Sector Description 1/ } & \multicolumn{1}{c}{ Examples of Peer-to-Peer Platforms 2/ } \\
\hline Couriers and delivery services & Deliveroo, Instacart, Postmates. \\
Digital currencies (financial intermediation, transactions) & Bitcoin, Ethereum, Ripple. \\
Financial services (crowdfunding, collaborative lending) & Funding Circle, Lending Club, Kickstarter, Prosper, SoFi. \\
Professional services & Fiverr, Freelancer, Taskrabbit, Thumbtack, Upwork. \\
Retail business (online sales, distribution, auctions) & Amazon, Craigslist, eBay, Etsy. \\
Software-, knowledge-, and media-sharing & Apple iTunes, Coursera, Dropbox, Wikipedia. \\
Transit And Ground Passenger Transportation & BlaBlaCar, Careem, Didi Chuxing, Lyft, Ola, Uber. \\
Traveler accommodation & Airbnb, Flipkey, Homeaway. \\
\hline
\end{tabular}

Source: Authors' own classification.

1/ These descriptors span multiple industrial classifications.

2/ Platforms operational at the time of writing.

A defining characteristic of these platforms is the technology and how it helps users interact and manage risk. The technology - much of it developed only recently, with the rest inherited from the first wave of P2P businesses-has allowed individuals to access functions previously too costly and available only to larger-scale businesses with economies of scale and scope. ${ }^{5}$ Web-based platforms, such as mobile applications on internet-enabled devices, provide easy access, for example, to payment intermediation functions, which allow rapid exchange of value between users at almost zero marginal cost.

Online platforms also provide reputational and feedback mechanisms, transaction histories, and opportunities for advertising and marketing, all improving the provision of information. As information becomes more symmetric, not only is adverse selection reduced, but trust between consumers and sellers also increases, even if they have not previously met. In addition, consumers can access a broader range of goods and services (through ownership or rental) customized to their tastes. Technology therefore provides quality control through user-based reviews and ratings systems, fulfilling roles that tight regulations and even natural monopolies could also play.

P2P platforms exert different degrees of control over their users. On most platforms, sellers are unrestricted in their access and can market themselves and set their own prices. These platforms focus more on improving search, match, marketing, and feedback functions for their users. Other platforms instead screen and select sellers, set the prices for services being offered, determine the matching of buyers and sellers, and impose strict codes of conduct, such as ride-sharing platforms which use semi-automated, algorithmic management systems (Rosenblatt and Stark, 2016).

\footnotetext{
${ }^{5}$ Recent P2P businesses have benefitted immensely from existing social networks and reputational technology refined over time by the first wave of e-commerce businesses, such as eBay. And now P2P platforms have instigated traditional businesses to adopt these technologies to compete and maintain market share.
} 
While revenue-generating models also differ from company to company, even within the same sector, Vaughan and Daverio (2016) note that most platforms adopt a fixed or variable commission-based approach, with commissions charged ranging from 1-2 percent for lending to up to 20 percent for transportation network companies, and with over 85 percent of the value of transactions facilitated received by the seller.

Another feature of P2P markets is that low barriers to entry allow buyers and sellers to switch roles easily and quickly. Such flexibility means that some individuals can engage either regularly (full-time) making it their primary source of income or irregularly at a lower frequency (part-time) to supplement other income. This flexibility to determine when to supply services can be of great value, as it reduces the opportunity cost of working and increases efficiency. Those participants in the labor- and capital-rental sectors typify this freedom for individuals to improve their labor-leisure trade-off. For example, by working a few more hours (or alternatively, renting out an asset for longer), P2P economy participants can loosen their budget constraints, expand their opportunity sets, and raise well-being.

One category of $\mathrm{P} 2 \mathrm{P}$ businesses has received a lot of attention and, for many, captures the spirit of the broader P2P economy (Schor and Fitzmaurice, 2015). For these businesses, platforms facilitate transactions by matching private individuals and allowing one party to "share" or temporarily rent the use of an underutilized asset to another (such as finance, human capital, labor, and physical capital). Sharing is therefore only one type of activity in the P2P economy and not a synonym for it. ${ }^{6}$ This paper considers all transactions (monetary or in-kind), either through sale or rental, that generate taxable income.

The next two sections gauge the size and impact of P2P markets, summarizing available data and evaluating research on the effects they have had on competition, efficiency, pricing, and labor opportunities. Understanding these elements will be useful when considering the tax treatment of P2P users later.

\section{A. The Scale of the Peer-to-Peer Economy}

The P2P economy is a global phenomenon with some of the largest platforms operating in Asia (Alibaba and DiDi Chuxing in China). While several platforms operate across multiple countries (Airbnb, Amazon, BlaBlaCar, and Uber), the key elements of certain platforms have instead been replicated locally (Casaferias and Zazcar in Brazil, Rappi in Colombia and Mexico, Ola in India, Careem in the Middle East).

Anecdotal evidence suggests that users on some of the largest platforms worldwide can number in the tens of millions (Table 2), suggesting that an enormous amount of transactions

\footnotetext{
${ }^{6}$ When defining the reach of the P2P economy, this paper does not cover certain P2P business models. For example, we do not consider businesses that provide subscription-based "on-demand" streaming services, such as, Apple Music, HBO, Netflix, Soundcloud, Spotify, and so on, where assets are not shared by individual owners.
} 
and income are being intermediated through these platforms. Moreover, results from a Pew Research Center survey suggests that 72 percent of American adults have used at least one of 11 different shared and on-demand services (Smith 2016). What is already clear is that many of the closely held P2P platforms themselves have attracted large amounts of capital and rapidly earned high valuations, which when scaled by the number of employees, exceeds many of the largest listed companies, including other listed P2P businesses (Figure 1).

Table 2. Number of Users on Some of the Largest P2P Platforms.

\begin{tabular}{lllc}
\hline Company & Headquarters & Service & Reported Users (millions) \\
\hline Airbnb & United States & Tourism & 100 \\
Alibaba & China & Commercial Marketplaces & 440 \\
Amazon & United States & Commercial Marketplaces & 300 \\
BlaBlaCar & France & Ridesharing & 40 \\
DiDi Chuxing & China & Ridesharing & 400 \\
Ebay & United States & Commercial Marketplaces & 170 \\
Lyft & United States & Ridesharing & 40 \\
Uber & United States & Ridesharing & 40 \\
\hline
\end{tabular}

Sources: Forbes, Fortune, Orbis, Reuters, and Wall Street Journal.

Figure 1. Value per Employee of Largest Listed Firms vs. Venture-backed P2P Businesses.

(US\$ million per employee)

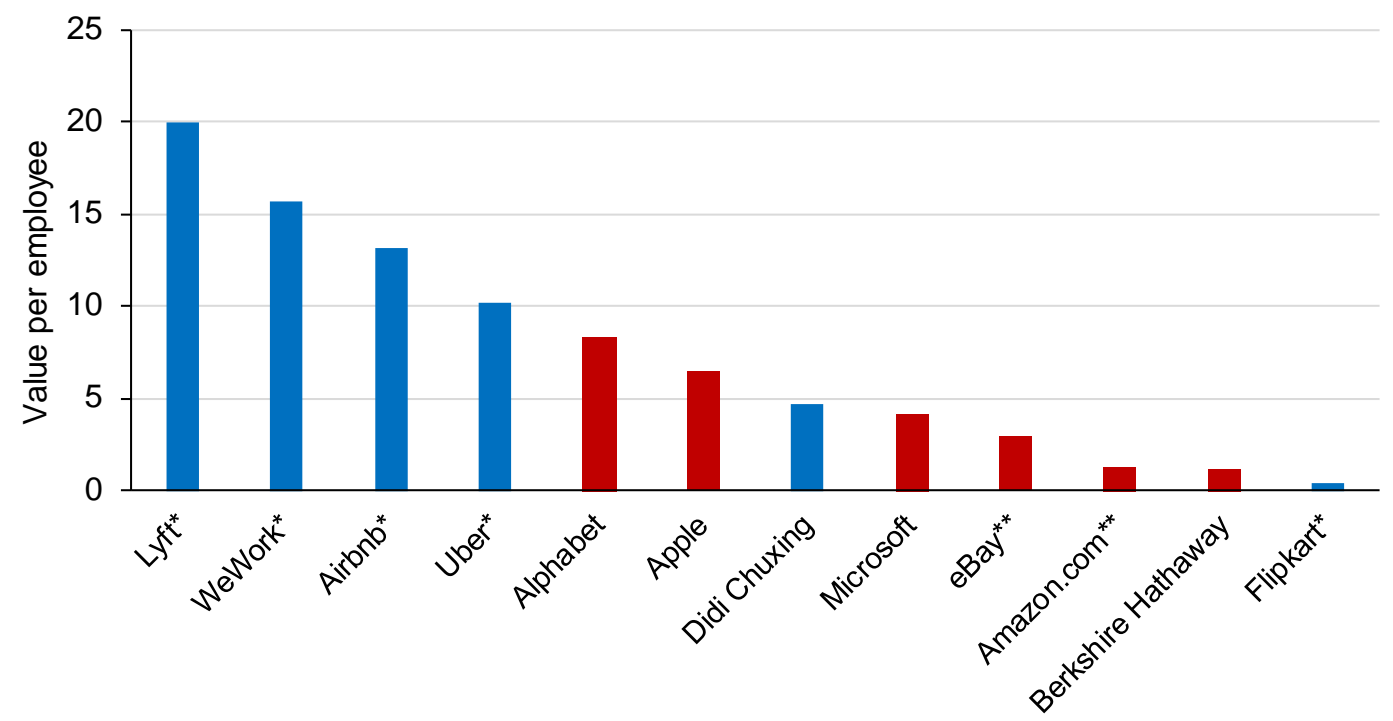

Sources: Dow Jones VentureSource, Orbis, and Wall Street Journal. Note: $\left(^{\star}\right)$ denotes closely-held, venture-backed P2P businesses. $\left(^{(\star}\right)$ denotes listed P2P businesses. Red bars denote listed businesses. 
However, platforms closely guard data on users and incomes. Short of ordering disclosure, many government agencies are developing other methods to estimate the value added of P2P activity to the economy. For example, the Office of National Statistics in the United Kingdom is considering how to measure the contribution of the P2P economy to GDP more accurately (Office of National Statistics 2016).

Nevertheless, several attempts have been made to ascertain the size and contribution of the P2P economy. Many of these studies have relied on secondary sources or proprietary data. Vaughan and Daverio (2016) examined the size of the P2P economy in five key sectors: accommodation, transportation, household services, professional services, and collaborative finance. Using a review of market, sectoral, and company data at a national, regional, and global level during 2013-15, they estimate that turnover on platforms in five key sectors of the P2P economy reached close to $€ 4$ billion ( 0.03 percent of EU-28 GDP) in Europe in 2015, facilitating around €28 billion (0.2 percent of EU-28 GDP) of transactions.

Three of the five sectors were also found to have expanded sales by several multiples in 2015 compared to 2014. Household services grew fastest, driven by the growing popularity of freelancer platforms and crowdsourced networks offering services such as ready-made food delivery or do-it-yourself tasks. Goudin (2016) examined the economic and social barriers and legislative gaps that could be holding back full implementation of the P2P economy across the European Union. The author estimated that the potential economic gains from employing underutilized capacity through P2P activities is $€ 572$ billion in annual consumption (4 percent of EU-28 GDP).

\section{B. Some Theory and Empirics on the Peer-to-Peer Economy}

\section{Shrinking Transaction Costs}

The P2P economy is a reversion to an almost preindustrial mode of organizing activity. Coase (1937) introduced the concept of "transaction costs"-later refined by Williamson (1981) — as the basic unit of analysis for determining how the organization of production developed historically into governance structures or "firms". While the price mechanism efficiently allocates resources in the market, it is costly due to frictions such as search, marketing, and negotiation over contract terms. Firms can economize such costs, for instance, by employing labor in open-ended employment contracts within "islands of conscious power", rather than repeatedly going to the market to negotiate short-term, taskbased contracts with labor providers. ${ }^{7}$

\footnotetext{
${ }^{7}$ Coase (1937) quoting Robertson (1923). One can therefore expect the P2P economy to expand rapidly in sectors where contracting costs are already relatively minimal and short-term contracts dominate. In addition, the resource-based view of the firm complements this approach to some extent, by identifying other competitive advantages that firms have over purely market-based interactions, e.g., intangibles such as "corporate culture".
} 
Rapid, efficient, arms-length transactions lie at the heart of the P2P economy, and the technology behind the platforms has gone a long way in overcoming costs that previously made many of these transactions too difficult for small businesses to contract and implement. At the same time, technological developments have allowed for ever more precise, flexible, and credible coordination on tasks and services between the two sides of the market. Furthermore, search and matching costs have been reduced to the point where individuals can now transact, including share assets, on a cross-border scale. Therefore, the minimum efficient scale - the level of production at which average cost is minimized and equal to marginal cost - is shrinking relative to demand in the market, encouraging a larger number of smaller business to enter. ${ }^{8}$

\section{A Short Primer on Two-sided Markets}

P2P marketplaces are examples of "two-sided markets”, where the decisions of one side affect the outcomes of the other (Caillaud and Jullien 2003; Ellison and Fudenberg 2003; Evans 2003; Rochet and Tirole 2003; Armstrong 2006; Rysman 2009). ${ }^{9}$ The interaction between the two sides gives rise to strong complementarities-notably, network and information externalities - where the value in transactions increases for both groups as the numbers on each side increase. While both sides are also typically populated by individuals, this does not preclude businesses from participating in the P2P economy, although they typically do not dominate it.

The academic literature on two-sided markets initially focused on how platforms set prices for both sides to ensure they choose to interact. Rochet and Tirole (2003) establish some of the key theoretical results, specifically how prices on both sides of the market depend jointly on the demand elasticities and marginal costs of each side. As Rysman (2009) notes, while prices typically fall as the price elasticity of demand increases in traditional markets, the effects could be magnified in a two-sided market. For instance, consider a market of buyers (side A) and sellers (side B). A lower price on side A will attract demandelastic consumers, which attracts greater supply or raises prices on side B (or both). By drawing in side $\mathrm{B}$, the value to the platform of having more buyers on side $\mathrm{A}$ increases, which leads to an even bigger price decrease and quantity increase on side $\mathrm{A}$, where the price elasticity of demand has increased.

\footnotetext{
${ }^{8}$ In some sectors, such as natural resources, the minimum efficient scale is large because of the high ratio of fixed to variable costs. In these cases, the sectors are more concentrated and dominated by a handful of major players.

${ }^{9}$ Popular examples of such markets when the literature was first developing include: newspaper companies attempting to attract both readers and advertisers; video gaming systems, where the intermediary is the console producer and the two sets of agents are consumers and video game developers; and payment card systems, where both consumers and merchants value each other's participation.
} 
Bolt and Tieman (2008) loosen some of the assumptions in Rochet and Tirole (2003) to show that a skewed pricing result can boost the demand for services supplied over the platform, by using the less elastic side (C) of the market to subsidize the more elastic side (D). Every agent on the high-elasticity low-price side (D) of the market will connect to the platform and the other lower-elasticity higher-price side $(\mathrm{C})$ is therefore also encouraged to join to benefit from the full participation. Since side $C$ is more price inelastic, the platform can charge a higher price to extract greater rents from them. Competition in two-sided markets adds an additional dimension to pricing. With two competing platforms pricing to consumers and sellers, if one lowers the consumer price, it will attract consumers from the competing platform. This reduces the value of the second platform to users, and hence leads to a larger demand for the first platform and eventually a larger supply. Hence, the implications of the joint interaction of pricing in two-sided markets is even more pronounced in competitive markets.

Taxation in two-sided markets has also been examined (see, for example, Kind, Koethenbuerger, and Schjelderup 2008, 2010; Bourreau, Caillaud, and De Nijs 2017). Once again demand complementarities alter the results from traditional one-sided markets. For a monopoly platform, Kind, Koethenbuerger, and Schjelderup (2008) shows how an increase in ad valorem tax on one side of the market may result in overproduction (compared to the social optimum), with an increase in output on both sides of the market. For example, an increase in the ad valorem tax on side E may lead the platform to raise sales on side $\mathrm{F}$. To do so, the platform would need to increase output on both side $\mathrm{E}$ and $\mathrm{F}$ given their mutual dependence. A specific tax would not have such an effect as it increases marginal cost, decreasing output. To prevent oversupply, positive specific taxes or negative ad valorem taxes should be used in two-sided markets. Therefore, ad valorem taxes, which are traditionally less distortionary, no longer dominate specific taxes and instead the latter may be preferable to the former. ${ }^{10}$

While network externalities remain an essential feature, another important feature of the recent $\mathrm{P} 2 \mathrm{P}$ market is that the two sides of the market are no longer distinct. For example, being either an owner or a renter is an endogenous decision that users of the platform make, and more of the former implies fewer of the latter (and vice versa). Therefore, skewing pricing and taxation to one side of the market may no longer be desirable, as it can create an imbalance in the supply and demand for the shared resource. Benjaafar and others (2015) build a stylized model to understand the determinants of ownership and rental. The level of the rental price determines the degree of ownership and usage levels and with a sufficiently

\footnotetext{
${ }^{10}$ Bourreau, Caillaud, and De Nijs (2017) analyze the effects of taxation for a two-sided platform where data collection increases the quality of service to users and the value to advertisers. Their analysis shows that taxes on data collection may reduce the volume of sales and hence lower indirect tax revenues. It may also lead platforms to switch business models and start collecting subscription fees from users. Instead, an ad valorem tax on advertising revenues is superior to a tax on data.
} 
high rental price, higher ownership and usage levels are possible even when the cost of ownership is high.

Horton and Zeckhauser (2016) also build a simple framework to understand how P2P markets can develop given the purchase price of the asset to be shared, valuations of owners and renters, the number of owners and renters, and the costs of bringing the asset to market. While durable goods that are expensive, used infrequently, but whose usage can be planned are among the best candidates for rental, P2P rental markets can only develop if prices and valuations are such that there are stocks of both owners and renters. ${ }^{11}$ The introduction of $\mathrm{P} 2 \mathrm{P}$ rentals is found to decrease ownership but increase utilization with the biggest gains in surplus accruing to renters who gain access to the good.

\section{Some Empirical Results from the Literature}

Recent empirical work on P2P markets has produced valuable insights into the impact $\mathrm{P} 2 \mathrm{P}$ activities are having on competition, prices, and labor markets. P2P businesses have been found to boost efficiency and supply by reducing transaction costs for search, matching, and overheads. On the demand side, this has translated into lower prices, convenience, and a greater variety. Cullen and Farronato (2015) use data from TaskRabbit to examine how P2P labor markets equilibrate highly variable demand and supply when matches need to be made both rapidly and locally. They find that labor supply is highly elastic, with increases in demand matched by increases in supply per worker with little or no impact on price. ${ }^{12}$ The effects of competition are also potentially showing up in service quality: Wallsten (2015) presents suggestive evidence from Chicago that consumer complaints for traditional taxis fell following the entry of Uber.

Are P2P businesses therefore displacing and undermining existing businesses? Zervas, Proserpio, and Byers (2017) find that Airbnb is winning customers from hotels that cater to the lower end of the market. Their presence has lowered revenues by around 8-10 percentage points in some segments as incumbents are forced to lower prices. In addition, the gap between high and low-season prices has narrowed as the P2P platforms can flexibly scale supply during periods of peak demand.

\footnotetext{
${ }^{11} \mathrm{P} 2 \mathrm{P}$ rental activities can therefore also have price effects on durable goods with secondary markets. For example, Fraiberger and Sundarajan (2016) use data from car-sharing company Getaround to calibrate a model of P2P car rental. Their analysis shows both a shift away from asset ownership (by below-median income consumers) and a decline in the price of second-hand assets.

${ }^{12}$ Lower prices also mean that consumers capture greater surpluses. Cohen and others (2016) use big data from Uber's surge pricing algorithm to recover price elasticities of demand to build a short-run demand curve. Using this, the authors calculate that the low-cost portion of the ride-sharing service managed to generate an overall consumer surplus of $\$ 6.8$ billion for consumers in 2015. The estimated consumer surplus is approximately 1.6 times as large as consumer expenditures.
} 
Farronato and Fradkin (2016) use the market for short-term accommodation to study the determinants of Airbnb growth and its effects on the industry. They find that across major U.S. cities, a larger Airbnb presence is associated with low opportunity costs of renting out spare rooms, high investment costs of building hotels, and high demand volatility.

Furthermore, a 10-percentage-point increase in the size of Airbnb reduces hotel revenue by 0.6 percentage points. Neeser (2015) does not find the same revenue effects, but offers evidence that Airbnb may have pushed down prices in Nordic countries. For ride-sharing, there are several signs that Uber is securing market share at the expense of existing taxi firms, such as the falling price of medallions (a city-issued license to operate a taxi) in the City of New York and notable bankruptcies in recent years, such as Yellow Cab in San Francisco.

However, firms can retain some advantages over P2P sellers. The former can still enjoy economies of scale and expertise in minimizing certain types of transaction costs. For example, Edelman and Geradin (2015) note how a conventional hotel can use a single front desk to process the check-in for hundreds of guests-a common source of friction for property sharing. They also point out that, unsurprisingly, P2P rental platforms are investing heavily to replicate these functions. In addition to these platform-lead efforts, a burgeoning industry is now providing complementary services to P2P activities.

The P2P economy has also had a significant impact on labor markets, particularly for lower-skilled jobs. Hall and Krueger (2015) assert that the Uber platform is bringing greater wage-earning opportunities to more people by allowing for much more flexible work arrangements. At the same time, the profile of these drivers is found to be closer to the average employee in the workforce in age and education, as opposed to the profile for more traditional taxi drivers and chauffeurs. Whether these new drivers are displacing existing taxi drivers is still difficult to determine, as is whether these drivers have re-entered the workforce as part of these ride-sharing platforms.

Manyika and others (2016) used existing data and workforce surveys to understand the rise of "independent work" in the P2P economy. They estimated that the number of independent earners ranges from 54 million to 68 million in the United States and from 60 million to 94 million in the EU-15. Therefore, between 20-30 percent of the working-age population in the United States and the EU-15, is believed to engage in such independent work. However, the contingent nature of such independent work-notably "zero-hour" contracts - have been blamed for exposing individuals to excessive job insecurity and insufficient benefits and social insurance (Brinkley 2013). ${ }^{13}$ The P2P economy could also be

\footnotetext{
${ }^{13}$ The issue of adequate social protection is garnering increasing attention from governments. In Europe, principle 12 of the European Commission’s ‘European Pillar on Social Rights' specifies that workers and, under comparable conditions, the self-employed have the right to adequate social protection (European Commission, 2017). In the United Kingdom, the 'Taylor Review of Modern Work Practices', released in July 2017, reviewed modern employment practices and set out a seven-step national strategy for "good work" in the United
} 
weakening worker bargaining power due to both the decentralized nature of interactions and, in some cases, the control exerted by the platform-with implications for wage and inflation pressures. Bernhardt (2014) notes that while it has been hard to find evidence of a strong, unambiguous shift toward nonstandard or contingent forms of work in aggregate dataespecially in contrast to the dramatic increase in wage inequality-this is not to say that there have been no changes in the workplace.

\section{Key TaX-Relevant Features of the Peer-to-Peer Economy}

This section highlights features of the P2P economy that are particularly relevant for tax policy and administrative design. These relate to both $\mathrm{P} 2 \mathrm{P}$ users and the platform.

\section{A. Growth and Classification of P2P Activities}

The previous section noted one of the defining characteristics of the P2P economy, namely the atomistic interactions among a population of highly dispersed users. The ease-ofaccess and flexibility of the $\mathrm{P} 2 \mathrm{P}$ economy means that the number of people transacting over digital platforms has increased substantially over the last few years.

While there is no clear preference a priori for how to operate within the P2P economy, the small scale and informality of the engagement means that most individuals carry out P2P activities as self-employed businesses. However, these (unincorporated) activities could just as easily be carried out by individuals that have incorporated their businesses, and tax policy can determine this choice. Data on the number of businesses in the United States with zero employees (nonemployers) provide some confirmation by showing a marked increase in the transportation sector and to a lesser extent in the accommodation sector in the last five years (see Hathaway and Muro 2013; and Figure 2). This increase is also significantly larger than the growth in firms with employees.

Business classification has become increasingly controversial for those platforms that manage their users more actively, most notably in the ride-sharing sector. The resulting legal challenges have seen sellers demanding employment rights. From a tax perspective, employment classification has implications for the compliance and reporting obligations of both the platform and the sellers. Tax legislation typically classifies labor into salaried employees or independent contractors (self-employed). Employers withhold payroll taxes and social security contributions on behalf of their employees, while the self-employed are responsible for filing and paying their own taxes and social contributions. Even though mechanisms already exist to address such classification issues in some sectors-for example, in the construction sector, where multi-factor tests are used to determine the appropriate

Kingdom, calling for equal treatment between those who work through P2P platforms ("Dependent Contractors”) and those who do not (Department for Business, Energy \& Industrial Strategy, 2017).

(continued...) 
worker classification - the ambiguity in the $\mathrm{P} 2 \mathrm{P}$ economy is yet to be resolved. This is clear from the outcomes of recent court rulings across countries. ${ }^{14}$

Transforming all P2P sellers into employees would shift the burden of withholding and reporting to the platform. In some countries, the appropriate classification may also have an impact on direct tax revenues where the effective tax rate on the self-employed differs from that on employees. For indirect taxes, self-employed individuals are required to remit payments when sales income exceeds a certain threshold, and the platform is responsible for remitting taxes on any fees or commission charged for its intermediation services. However, if P2P sellers are restyled as employees, this division of responsibilities would also change and the platform would bear the full indirect tax liability on total sales generated. ${ }^{15}$ Even while the debate continues, some labor-intensive platforms are attempting to avoid this issue altogether by offering their sellers the option of participating either as part-time employees or independent contractors.

\footnotetext{
${ }^{14}$ In February 2017, a Brazilian court recognized P2P ride-sharing platforms as employers, while in March 2017, a Paris tribunal dismissed a French request for Uber to make social security payments to drivers. Some U.S. states (California, Florida, and Massachusetts) have also ruled in favor of Uber, stating that drivers are independent contractors, not employees. In late 2016, a British employment tribunal ruled in favor of two Uber drivers, entitling them to holiday pay, paid rest breaks, pension contributions, and the national minimum wage. However, this ruling opened the door for P2P sellers to be designated as a third category of "worker" falling between employee and self-employed.

${ }^{15}$ A related case was ongoing in the United Kingdom at the time of writing, where Mr. Jolyon Maugham from the Good Law Project is arguing for Uber to provide him a value-added tax (VAT) receipt for the taxi service he was provided. Should the court rule in his favor and classify Uber as a service provider (instead of a third-party platform intermediary for self-employed drivers), the U.K. tax authority would then be able to seek VAT payments for all rides Uber provided during the last four years, which are estimated in the order of hundreds of millions of pounds.
} 


\section{Figure 2. Small Business Trends in the United States}
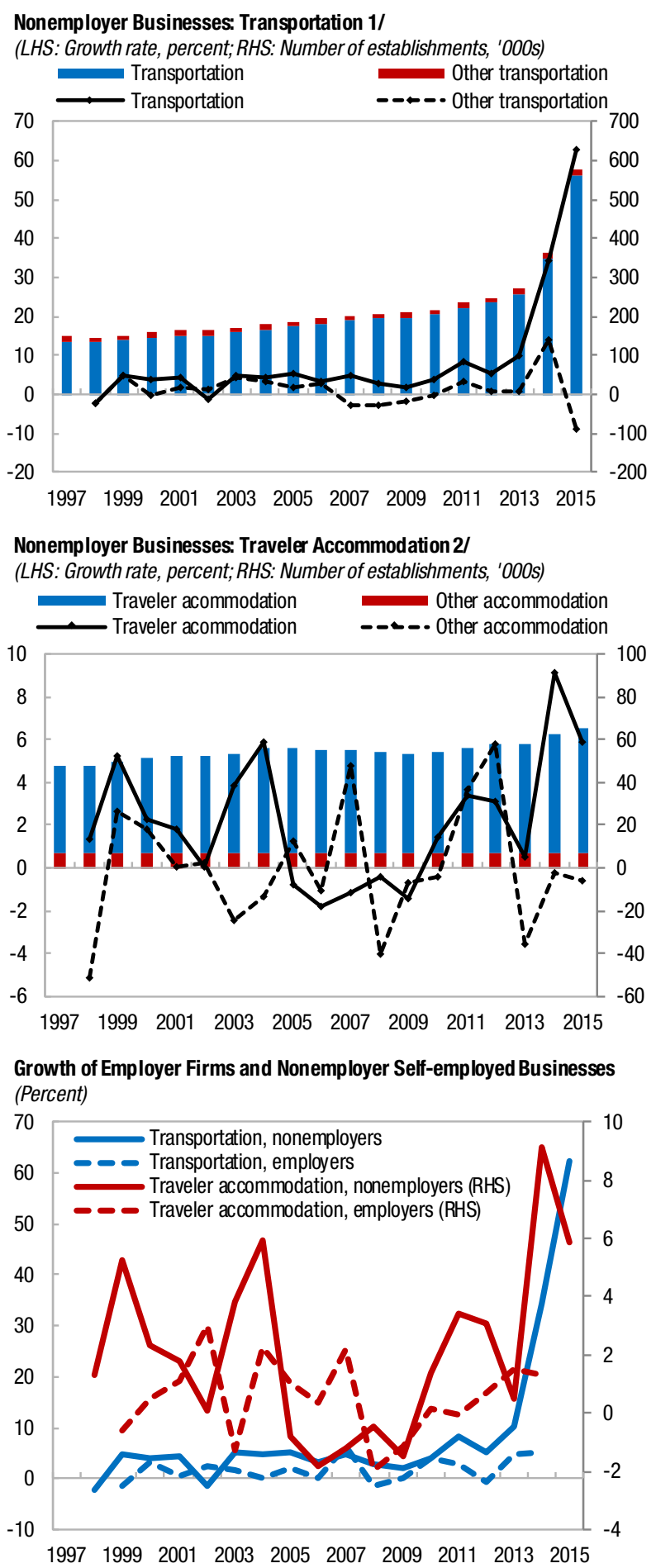

Source: United States Census Bureau.

1/ Transportation includes NAICS codes 4853 ("Taxi and Limousine Service") and 4859 ("Other Transit and Ground Passenger Transportation"). 2/ Traveler accommodation includes NAICS codes 7211 ("Traveler Accommodation") and 7213 ("Room and Boarding Houses"). 


\section{B. Low Incomes, Low Rents}

The level of engagement in the P2P economy also varies. Sellers can engage irregularly and at low frequency in P2P activity to supplement their income-for example, from low paid employment — or use it as their primary source. ${ }^{16}$ Farrell and Greig (2016a) use anonymized J.P. Morgan bank account data from approximately 260,000 customers in the United States over a three-year period to explore the degree of engagement. They find that certain groups subject to the greatest income volatility-18-24 year-olds, lower-income individuals, people residing in the Western United States - are most likely to use the P2P economy to smooth earnings. Income earned from labor-intensive P2P activities also helps offset drops in income earned off-platform (non-platform income), while income from capital-intensive P2P activities is used to supplement non-platform income. Individuals providing labor-intensive services are typically from the lower end of the income spectrum, while those providing capital-intensive services have higher average monthly income. At the same time, repeat usage of platforms falls off after the first month by up to one-third for labor-intensive activities and two-thirds for capital-intensive activities, suggesting more regular usage of the former.

While estimates of earnings can vary-for example, some have calculated that it is possible to earn a gross income of up to $\$ 50,000$ through ride-sharing in the United States-it is likely that, for many users, gross incomes earned through P2P activities are low. The average turnover can also vary widely depending on location and local demand. Without concrete data, it is hard to assess at what points along the distribution income is concentrated. However, anecdotal data for three cities from Airbnb suggests that annual incomes from accommodation rental are indeed low (Figure 3). Therefore, if we assume that the distribution of income earned is (1) concentrated at the low (left) end and (2) most P2P sellers are self-employed (and earn little other non-P2P economy-related income), then the progressivity of most personal income tax systems will mean that the effective average tax rates of these users will also be low. ${ }^{17}$

Even if gross income is not as low as many suspect, it is unclear whether P2P participants are generating large rents after offsetting costs. New entrants must incur significant fixed capital costs to be able to participate, while those that either rent or use their existing personal assets to provide a service face dramatically lower fixed costs and entry risk. Indeed, the $\mathrm{P} 2 \mathrm{P}$ economy has seen its most pronounced growth in sectors in which suppliers

\footnotetext{
16 There are also individuals who evolve into “power-sellers” or larger-scale ventures.

${ }^{17}$ Farrell and Greig (2016b) find evidence that average monthly earnings and participation on online platforms are waning. This could indicate saturation of some parts of the P2P economy, or more generally, cyclicality in its usage. Income from P2P activities might no longer be as lucrative as it was, especially as job growth recovers in some countries and better alternatives with greater benefits and job security materialize.
} 
make significant use of an otherwise underutilized personal asset for commercial purposes. Sellers do incur variable costs, however, including expenses from adapting their personal assets to commercial use.

\section{Figure 3. Imputed Income Distribution for Airbnb Hosts}

(Share of P2P Total Hosts)

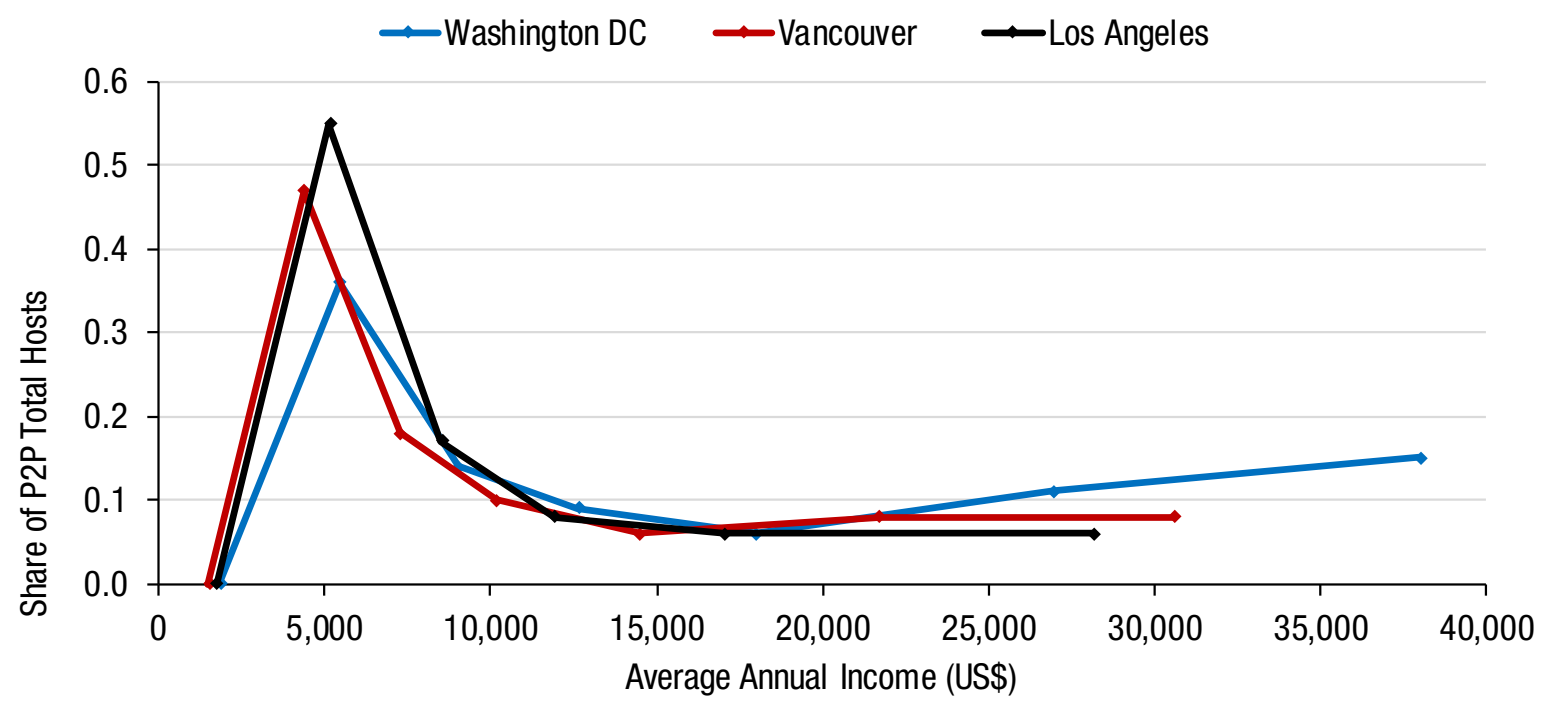

Source: Airbnb Inc. and authors' own calculations.

Notes: Figure combines binned distributions of nights per listing for three cities (Los Angeles, Vancouver, and Washington,

D.C.). These are combined with data on average incomes per night. These calculations assume zero correlation between (i) price per night and nights per year, and (ii) nights and multi-listing host status.

\section{Correcting for Externalities}

While the success of the P2P economy relies on positive network and information externalities, driven by the technology, externalities also arise from the outcome of the P2P activities themselves. For example, with increased ride-sharing, traffic congestion might increase or decrease in cities (Martin, Shaheen, and Lidicker 2010). Property-sharing could boost tourism and spillovers to local economies and the P2P business model can also bring previously undocumented activity into the formal economy (Box 1).

The presence of externalities could call for more direct tax policy intervention in the form of "Pigouvian" taxes or subsidies to discourage or encourage certain P2P activities. ${ }^{18}$

\footnotetext{
${ }^{18}$ Where certain sectors have emergent natural monopolies or oligopolies (such as ride-sharing), the government could even consider nationalizing platforms to administer prices and regulate congestion. The government could even optimize price-setting to meet some social objective (such as lower prices to subsidize low-income consumers).
} 
However, as discussed in the previous section, the nature of two-sided markets warrants caution in the types of tax instruments used, given the feedback between each side.

\section{P2P Platforms as Data Recorders}

Moving on to the P2P platforms themselves, their role as intermediaries means that they maintain a digital footprint of all business income generated by users. The data recorded by platforms allows them to act as third-party reporters and alleviate informational constraints for tax authorities. If direct access to the information held by platforms is not an option, they could instead have the P2P platform withhold taxes on P2P users and then remit these to the exchequer.

If data on income generated from P2P activities by individuals can be combined with income earned from other sources, governments could design better tax systems that can ameliorate the equity-efficiency trade-off that results from the inability to perfectly observe individuals’ work effort and earnings abilities (Jacobs 2017; Dabla-Norris and others 2017). Overall, the potential for alleviating compliance burdens on both users and governments appears significant, and if tax systems tailored to income and consumption patterns are possible, the current system of thresholds-imposed to trade off revenue gains with compliance losses - may become obsolete.

\section{How Should We TaX The Peer-to-Peer Economy?}

In determining tax policy, governments would need to assess the size and dynamics of P2P activity in their countries and evaluate whether their tax revenue potential and economic impact is sufficiently positive or negative to warrant either special tax structures or modifications to existing features of the tax system. ${ }^{19}$ Part of this assessment involves understanding whether activities in the same sector carried out by both P2P and traditional businesses are economically equivalent. Furthermore, issues relevant to cross-border transactions and small businesses more generally-beyond the P2P economy-must be considered.

An important guiding principle is that taxes should have minimal impact on the behavior of economic agents. However, governments may choose to target P2P activities, for example, to correct for externalities. Design considerations might alternatively be driven by the government's desire to ease the burden of compliance and administration for P2P users. This could be achieved by applying simplified tax policies or cooperating with the platform to obtain information from them on income to facilitate audit and verification of tax filing or to have them act as a withholding agent for tax collection.

\footnotetext{
${ }^{19}$ For example, the revenue authority in the United Kingdom has commissioned a survey of the P2P economy to understand the determinants of its size and growth and whether the tax treatment of income earned is a major deterrent to participating in it.
} 


\section{A. A Neutral or Targeted Treatment of P2P Businesses}

Should governments decide to target P2P businesses, they need to consider a number of factors. Evidence on the economic impact of P2P activities remains mixed-see Sections II and III. In addition, tax revenues raised directly from small businesses in general remain modest compared to the rest of the economy. While countries define their small business segments differently, findings suggest that they commonly account for less than 15 percent of domestic tax collections and often much less in low-income countries (IMF 2015). Assuming most P2P sellers are labor intensive with narrow profit margins and are therefore not generating large rents, it is important not to overstate the potential revenue gains from taxing them or even risks to current revenue. Income misreporting is also more likely, given more irregular, low frequency, and, therefore, lower income activity. Revenue potential will therefore depend on exploiting the number of small businesses rather than rents, as well as the responsiveness of reported income to tax rates and thresholds. ${ }^{20}$

As technology continues to eliminate transaction costs, increasingly efficient small businesses may better compete with and displace larger incumbents, as discussed in Section II. Any favorable P2P tax treatment would exacerbate this effect. Where incumbents are being displaced and replacement P2P activity remains below tax thresholds, governments will lose revenue as income and profits are dispersed across many smaller businesses instead of concentrated in large profitable companies. Governments could attempt to recoup this lost revenue by carefully adjusting rates and thresholds. However, if P2P businesses are both more efficient than existing methods of provision and generating positive spillovers, doing so could impose high disproportionate costs and stifle such developments.

Given the relative elasticities of buyers and sellers and their interdependencies, governments should be sensitive to the incidence of taxation. After all, the success of the P2P business model hinges on maintaining a sufficient network of buyers and sellers, that is, exploiting network externalities. A tax on only P2P businesses could shift the tax burden so as to deter participation from either the demand or the supply sides. P2P platforms have been hitherto apprehensive about levying or varying charges on either side, while also demanding equal tax treatment across rival platforms.

These demand complementarities also have the potential to lure previously undocumented merchants-for example, in the household services sector-onto platforms and therefore into the formal economy. Countries would benefit, in that less income would go unrecorded and therefore come into the tax net. Increasing the relative tax burden of P2P

\footnotetext{
${ }^{20}$ Furthermore, the growth in low-income P2P activities could lead to lower social security contributions, particularly if sellers remain below exemption thresholds. However, many of these sellers could still qualify for social benefits over time where eligibility requirements are minimal, leading to an underfunded social security system. Such problems could also worsen as technological developments continue to threaten employment and polarize the income distribution.
} 
sellers risks reversing this positive feedback loop, chasing sellers off the platforms and back into the informal sector. ${ }^{21}$ These dynamics may be particularly volatile in emerging market and developing economies with large informal economic sectors.

What have governments tried so far, if anything? As noted earlier, the P2P business model allows alternative provision of goods and services, while the actual goods and services themselves remain unchanged (accommodation, transportation). Recent tax policy measures have therefore focused on leveling the playing field between P2P sellers and traditional businesses, where differences in tax treatment exist (Box 2). These differences typically originated from unequal application of local or sector-specific taxes. Indeed, despite initial claims by ride-sharing and accommodation-rental P2P platforms that they were providing services different to existing taxi and hotel businesses, many governments have recognized their economic equivalence.

For example, occupancy and tourism taxes, which previously only applied to traditional hotels, are now applied to transactions within the P2P accommodation rental sector. In ridesharing, the general sales tax in Australia and the harmonized sales tax in Canada applied previously only to traditional taxi drivers and was viewed as a disadvantage. With its extension to ride-sharing, this imbalance has been redressed. However, in most countries, license fees in some parts of the taxi industry currently do not apply to P2P drivers in the ride-sharing industry.

\section{B. Tax Thresholds}

Governments could choose to lower tax thresholds to bring a larger portion of small business activity into the tax system. If so, they need to be sensitive to behavioral impacts and their own administrative costs. Figure 4 illustrates how low average annual incomes are in the P2P accommodation rental sector, already falling below current indirect tax thresholds.

The choice of tax threshold can in part be derived as a function of the size distribution of small businesses and the associated revenue-cost trade-off facing governments. An increase in the left portion of the size distribution would eventually alter this balance, leading to a lower threshold that would bring a higher share of self-employed businesses into the tax system. However, lower tax thresholds come with the risk of increasing not only the administrative costs for both governments and small businesses, but also the noncompliance (both legal and illegal) of the latter.

In a world of taxpayers with different compliance preferences, Kanbur and Keen (2014) show that when they are largely honest and compliant, the optimal tax threshold is sensitive

\footnotetext{
${ }^{21}$ This effect may be less pronounced in markets where demand for such services is high and relatively inelastic - that is, where consumers value the convenience and quality assurances of using the platform rather than individually searching and contracting for services in the informal economy — such that the incidence of taxation falls primarily on consumers.
} 
to changes in the size distribution of businesses and must be set to ensure that businesses do not choose to avoid taxes by (legally) adjusting their incomes below the threshold. Where, instead, evasion is dominant-for example, in economies with less-developed tax administrations - thresholds should be set higher than would otherwise be optimal to discourage the (illegal) concealment of income.

\section{Figure 4: Average Income from Airbnb Inc. by Country vs. Indirect Tax Thresholds} (US\$ thousands)

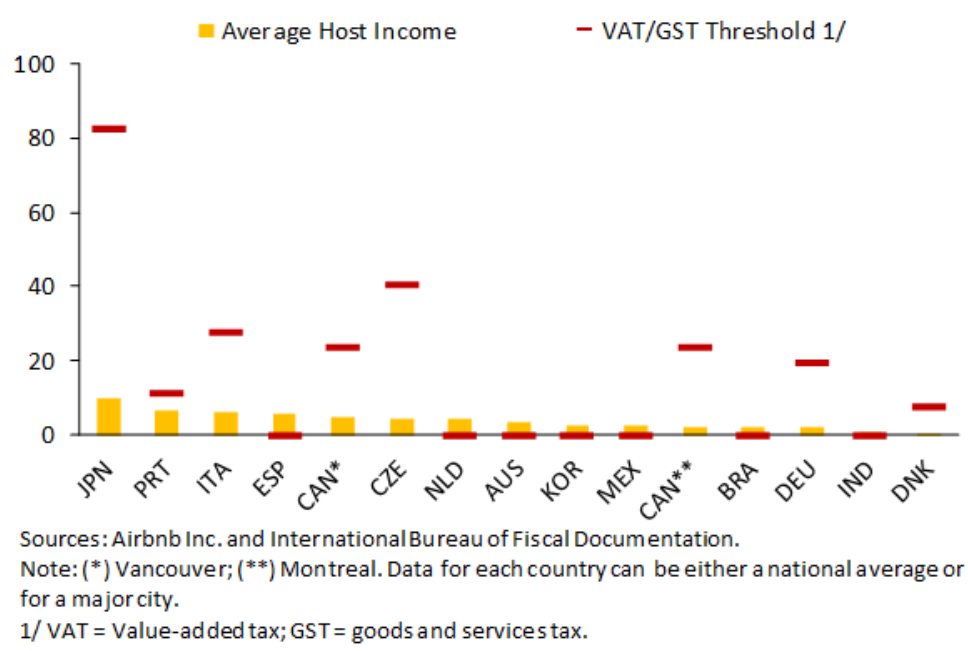

Keen and Mintz (2004) focus on a special case of thresholds for the value-added tax where compliance is perfect and there are no behavioral responses. This specification implies setting lower thresholds on activities characterized by higher ratios of value-added to sales. Therefore, highly profitable or labor-intensive activities (services), which form an important part of the P2P economy, would be subject to relatively low thresholds. The technology underlying the $\mathrm{P} 2 \mathrm{P}$ economy also presents opportunities to alleviate the trade-off between revenue gains and compliance costs by lowering the former.

\section{Cross-Border Taxation of P2P Services}

Typically, many P2P transactions are based around local (nontradable) services, such as ride-sharing and delivery services. However, some services (and intangibles) are now being increasingly provided across countries, for example, through remote-working platforms. In a cross-border setting, governments must be reminded of the risks of double taxation and unintended non-taxation, for example, arising from inconsistencies in the application of indirect taxes to services. Taxing final consumption in the jurisdiction in which it occurs, according to the destination principle, would not only help overcome such risks, but also benefit local and national governments. To this end, the OECD has developed international value-added tax (VAT) and goods and services tax (GST) guidelines to minimize irregularities. 


\section{Treatment of Capital and Labor}

Where capital and labor are combined to deliver a P2P service, the income earned is a mixture of the returns to both inputs. How governments choose to tax labor and capital income has implications for investment and how businesses grow. ${ }^{22}$ However, the optimal taxation of capital income, under specific assumptions, suggests lower rates than on labor (for example, see Atkinson and Stiglitz 1976; Judd 1985; and Chamley 1986). In practice, capital is taxed differently depending on the organizational form (for example, corporate or noncorporate), the difference in present value between the tax depreciation allowance rules and real (economic) depreciation, the source of financing (such as debt or equity), and firm size (in some countries, small firms can expense or immediately write off their capital investments rather than depreciate them over time).

Whether the capital income of P2P businesses is more (or less) punitively taxed than the capital income of competing traditional businesses is difficult to determine given differences in treatment. ${ }^{23}$ Furthermore, different asset types face different effective tax rates because tax depreciation rules do not uniformly relate to an asset's economic depreciation. The taxation of capital might therefore be different between different types of capital-intensive P2P businesses, as well as between P2P businesses and existing businesses. These differences would be determined by how investment is financed and capital goods are expensed (such as fully under a cash-flow tax or depreciation over time).

Since P2P businesses can be unincorporated or incorporated, the relationship between capital and labor taxation - expressed through the interplay between corporate and personal income tax rates-becomes important. With more and more self-employed P2P businesses, any pre-existing tax differentials between the corporate and personal income tax schedules become a greater revenue risk should a large swathe choose to incorporate. Such differentials are particularly relevant for those P2P users already paying higher marginal personal income tax rates (such as those that engage full-time in the P2P economy or use it to supplement other sources of income). ${ }^{24}$

\footnotetext{
22 This touches on a foundational and familiar issue in taxation: whether a single rate schedule should apply to the aggregate of different sources of income (a "global" comprehensive income approach) or different schedules should apply to different sources of income (a "schedular" approach). A global approach has the appeal of eliminating any incentive to artificially transform one kind of income into another, since the taxpayer faces the same marginal tax rate on all types of income. It also satisfies a version of horizontal equity-that is, everyone with the same purchasing power pays the same amount of tax-when tax liability is determined by annual income (rather than lifetime income).

23 The relative advantage or disadvantage to capital income will also depend on the nature of comparison within and across sectors. For the accommodation rental sector, is the correct comparison a hotel versus a single landlord or a group of properties that generate equivalent income to the hotel?

${ }^{24}$ Within the personal income tax system, some countries even deliberately maintain separate personal income tax schedules for self-employed businesses and employees. Where lower for the latter, this could be motivated
}

(continued...) 


\section{E. A Presumptive Tax System for the P2P Economy}

Section III noted how the expansion of atomized P2P sales may give rise to an enforcement challenge for tax authorities. At the same time, even though P2P sellers operate mostly as sole proprietors earning low incomes and profits, they are faced with the same compliance burdens as other self-employed businesses. The nature of many P2P activities involving the use of personal assets for business purposes adds further complexity in terms of the tracking and allocation of expenses. Indeed, difficulties in complying with tax obligations appears to have proliferated a business of tax advisors targeted at the P2P economy. However, the small amounts of taxable income involved, which may nonetheless be large in aggregate, raise the question of whether it is both efficient for taxpayers to be seeking to comply with and for governments to be enforcing complex legislation.

A de minimis tax and reporting threshold for the personal income tax is one option to ease and simplify the tax administration burden. As with the VAT threshold, the precise level of the threshold will depend on administrative costs versus revenue benefits from taxing P2P businesses. The United Kingdom estimates that its new tax-free allowance will impact 700,000 participants in the P2P economy (Box 2, Table 2.1) with an administrative saving of $£ 20$ million per year for individuals who either no longer need to file returns or calculate expenses. With better data from the sector, governments can better calibrate the threshold to balance their administrative costs with revenue objectives.

Introducing a presumptive regime for small businesses below a certain threshold into the general tax system is another option, which is already in place in many countries. This system helps reduce the compliance burden on taxpayers with very low turnover and the corresponding administrative burden of auditing such taxpayers. At its simplest, a low, uniform tax rate is applied to the gross income of P2P sellers. Indeed, in 2016, the Italian government proposed a requirement for platforms to withhold a fixed 10 percent tax on all P2P transactions.

Determining the appropriate flat rate(s) for all P2P businesses is an important choice for governments. They must consider that sellers earn income from both multiple P2P platforms and off-platform (for example, through regular employment), as well as their limited knowledge of each sector's typical profitability.

Furthermore, a single rate could be regressive, something which could be alleviated by levying a nonfinal withholding tax and allowing individuals to file a tax return at the end of the year based on their actual income and costs. However, such reconciliation undermines the desired simplification and lower administrative burden. Either introducing a simple basic

by a belief that self-employed businesses are less compliant. Where lower for the former, this could be to incentivize entrepreneurial activity. 
income exemption or designing a multi-tier rate structure of withholding rates would also introduce some progressivity into the system (Thomas 2017). Then again, the latter would have to be applied separately by each platform, possibly creating incentives for P2P sellers to deliberately spread their activity across several platforms. ${ }^{25}$ Furthermore, such a parallel schedular system for the P2P sector would introduce undesirable complexity and distortions into a country's tax regime.

A presumptive regime can alternatively focus on simplifying the reporting of costs. In a world in which P2P platforms automatically share information on incomes earned by sellers, one possibility would be the introduction of an optional standard business deduction from gross receipts. The United Kingdom has taken this approach through its allowance on trading and property income, targeted at the P2P economy (see Box 2). Thomas (2017) suggests an optional standardized deduction for the P2P sectors of 60 percent of the workers' gross receipts to be deducted in lieu of actual business expenses, eliminating the need to track and report business expenses.

Oei and Ring (2016) also suggest the use of safe harbors to define the scope for allowable deductions. Such standardized deductions would ease the compliance burden significantly and would still allow for the appropriate marginal tax rate to apply as per the country's tax schedule, once all sources of an individual's income are considered. In the United Kingdom, the construction industry scheme is designed to minimize tax evasion given the large number of mobile self-employed subcontractors. It allows standardized deductions from payments made by contractors to subcontractors, which count as advanced payments towards the subcontractor's tax and social security contributions.

The difficulty of designing an efficient and equitable method of taxing the income of P2P businesses reinvigorates the debate behind systems such as the Hall-Rabushka "flat tax" for the broader economy (not just small businesses). This scheme works by assessing a flat-rate tax on all businesses (corporate or otherwise), while allowing wages, pension contributions, materials costs, and capital investments to be deducted from the tax base. Individuals (or households) are assessed at the same flat rate on wages and pension benefits above a high basic income exemption. No other income is taxable, and no other deductions are allowed.

Of course, while many countries have enacted special regimes for certain small business sectors, such measures also raise questions about the desirability of a specialized tax regime for the P2P economy or whether such principles should apply more broadly to the small

\footnotetext{
${ }^{25}$ To the extent that income volatility could be higher for P2P businesses, given the irregularity of engagement, another alternative could be to apply a flat rate tax to the average income over a fixed number of years. The average method can provide tax benefits if there are fluctuations in the income from one year to another and the tax system is strongly progressive. In the United States, for example, Schedule J is the Internal Revenue Service form used when to average their fishing or farming income. Whereas this method is reserved the agriculture and forestry sectors in some countries it may also be an option for small P2P enterprises. However, P2P income can also be used to reduced volatility, given opportunities to earn income across multiple activities.
} 
business sector. At the same time, many individuals operate on multiple platforms both within and across different sectors. Therefore, it is important to consider whether special regimes should be applied uniformly across sectors or customized given that individuals earn multiple streams of income from different P2P activities.

\section{F. Exploiting Technology to Improve Tax Administration}

As the onus is on the self-employed individual to report income earned, monitoring a growing number of small-scale P2P participants-with fluid movement in and out of the P2P economy - will become extremely costly for tax authorities. ${ }^{26}$ Noncompliance for small businesses is typically very high, and IMF (2015) reports that error rates of over 40 percent are found in small businesses, even in advanced countries. As noted earlier, the use of personal assets for business purposes for P2P activities involving adds further difficulty in verifying expenses, which can also easily be misreported in error or manipulated.

However, the critical role of the digital platform in facilitating and intermediating P2P transactions presents an important opportunity for tax administrators to authenticate the incomes reported by P2P sellers. Many countries are now looking to cooperate with platforms to access this information. Others have considered extending the powers of the tax authority to acquire data from platforms, or to require them to automatically report those P2P sellers who have earned income above any tax-free thresholds. For example, the United Kingdom has recently enacted legislation extending the powers of the tax authority to acquire data from digital platforms.

In the United States, all individuals or organizations who pay independent contractors at least $\$ 600$ during the year must file a Form 1099-MISC to report these payments to the tax authorities. For collaborative finance platforms, any net interest earnings above \$10 are reported on Form1099-OID. The contractor will also receive a copy of these forms, providing a definitive record of income earned throughout the year. P2P platforms should, in principle, be fulfilling these reporting requirements, given that they classify their sellers as independent contractors. In doing so, they would also provide the tax authorities with data on turnover which can be cross-checked with the tax filings of those same individuals. However, as Oei and Ring (2016) note, many major platforms have chosen to classify themselves in the U.S. as "payment facilitators" — a classification originally intended for financial intermediaries - which have obligations to report gross earnings for all U.S. users who earn over $\$ 20,000$ and have 200 or more transactions in the calendar year. The vast majority of

\footnotetext{
${ }^{26}$ Many governments have recognized the need to issue guidance to clarify the applicable tax regime and Australia, Canada, the United Kingdom, and the United States are examples of countries that have recently issued specific guidance clarifying the tax obligations for users of the P2P economy. Several platforms have also taken responsibility for informing their taxpayers about their responsibilities and tax obligations, with most platforms providing some brief guidance on their website. Airbnb appears to go further, withholding 28 percent of income from U.S. users who do not provide their taxpayer information.
} 
P2P sellers are unlikely to meet these criteria, reinforcing the importance of appropriately setting reporting thresholds.

However, the willingness of P2P platforms (and participants) to grant such access to information is a function of both institutional and sociopolitical factors. Platforms may be reluctant to provide such information, to protect the privacy of users, or may only do so in exchange for certain concessions. Where trust in government is low or rule of law is weak, information sharing with government may even deter participation in the P2P market.

The platform's role in intermediating electronic payments for $\mathrm{P} 2 \mathrm{P}$ transactions also highlights the potential for its role as a tax-collection agent. This appears straightforward for indirect taxes on the gross value of the transaction. A handful of platforms have already agreed to collect and remit taxes on behalf of their users. For example, in the accommodation-rental sector, Airbnb now plays the role of tax collector and remitter for hotel and tourist taxes in four countries.

This approach is also being tested for indirect taxes. ${ }^{27}$ In 2015, India introduced legislation which requires digital platforms to charge and remit service taxes due on the income of sellers. The possibilities for the platform to act as a collection agent can lower the cost of indirect tax administration, increasing the feasibility of a low or zero threshold. However, several technical issues remain unresolved, including how sellers can claim credits on inputs should the platform withhold indirect tax on their sales on their behalf. A flat rate scheme is one way to address this shortcoming. Such a scheme currently operates for farmers in the United Kingdom, who can apply a reduced VAT rate, which reflects a deemed credit on inputs when goods or services are sold to VAT-registered customers. ${ }^{28}$ Such a system could be administered by the platform, which would withhold and remit the VAT to the government.

For taxes on income, the situation becomes more complicated. To calculate the correct liability, most tax systems require self-employed individuals to aggregate all income earned and deduct costs before applying the appropriate schedule of exemptions and marginal tax rates. If an individual's entire income were earned on a single platform, platforms could withhold income taxes (as for employees) after deducting an estimate for costs — or if individuals provided a record of expenses to the platform. However, as anecdotal evidence suggests, sellers earn small amounts of income through multiple P2P activities_ or are engaged in the same activity across multiple platforms-platforms do not have complete information on sellers' total income and costs and therefore cannot perform such

\footnotetext{
${ }^{27}$ India introduced a full-fledged goods and services tax in July 2017. This unified national tax replaced multiple cascading indirect taxes levied by the central and state governments.

${ }^{28}$ For turnover of less than $£ 150,000$, the United Kingdom applies different flat VAT rates across 54 different types of business, ranging from 4 percent (such as on retailing food, confectionery, tobacco, newspapers, or children's clothing) to 14.5 percent (such as on an architect, civil and structural engineer, or surveyor).
} 
withholding. Without the full income and cost profile for sellers, anything more than a blunt withholding instrument on gross income earned through that platform-either as a final tax or a prepayment-is currently difficult for the platform to administer.

\section{CONCLUSiOnS}

The P2P economy continues to grow and gain prominence worldwide as a means of organizing activity and providing services, supported by essential improvements in technology. It has also been proving itself an increasingly attractive option for users to make a living. As facets of the P2P economy continue to seep into everyday functions-in many cases usurping existing businesses - governments will need to understand and develop opportunities to mobilize revenue from this sector. This paper attempts to both consolidate and set out issues around the taxation of this range of activities, reviewing the current tax system and the features of the P2P economy that could be a deciding factor in its future tax treatment.

A definitive approach is not immediately obvious, and depends on whether the government wants to minimize differences between traditional and P2P businesses (if any) or differentiate between them through the tax system if one is preferred over the other. However, the paper has highlighted that several of the issues associated with taxing P2P businesses are familiar, while the presence of platforms presents some important new opportunities. In this sense, the emergence of P2P activities does not seem to be driving a radical rethink of the tax system or the principles upon which it is based. Instead, the P2P economy — should it continue to grow-is forcing tax policy and administration to reconsider old trade-offs in a new light.

With the growth in P2P sellers, the number of unincorporated small businesses is increasing at the lower end of the gross income distribution. These businesses may displace larger firms and reinforce existing well-known challenges for taxing large numbers of small businesses, especially if formalization adds to the influx. Taxes are usually not only more difficult to collect from small businesses, but can be that much more distortionary given the aptitude small businesses can display at avoiding and evading them. The presence of even more small businesses is also altering the revenue-compliance trade-off that has determined the choice of tax thresholds in the past: governments could consider lowering thresholds if distributional shifts suggest revenue gains outweigh administrative burdens. Alternatively, special tax rules for small businesses can help, but the nature of P2P activity (and the dynamics of two-sided markets) could amplify both the behavioral impact as well as their possible benefits and costs. It is unclear how to balance the need for revenue with the distortionary impact of any special tax treatment, and, in time, the P2P economy could grow to such an extent that these special rules might become redundant—or even the norm.

Mercifully, the P2P platforms presents an important opportunity for both tax policy and administration. As online intermediaries, they record data on the myriad of transactions 
taking place in the virtual markets they oversee. Governments can cooperate with them to access this data, which would undoubtedly alleviate information constraints and strengthen enforcement and allow better quantification of activity that had previously been misreported or undocumented. Access to such data might one day lead to the creation of a connected taxpayer database which could provide a complete profile of the activity and earnings of individuals (for example, linked with employee withholding systems and other taxpayer registers).

While there might still be some way to go before reaching such an environment, platforms can already act as custodians for the tax administration by withholding tax on behalf of sellers, something which seems relatively straightforward for indirect taxes. Such arrangements could help ease compliance and administration while raising revenue, particularly in low-capacity countries, and, again, allow tax authorities to revisit the revenuecompliance trade-off. However, attempting to levy direct taxes through such withholding arrangements is more difficult, as P2P sellers rarely use one platform exclusively and are likely to be mixing many different streams of income from different activities (on and offplatform, self-employment, and employment). At present, a simplified system of withholding fixed amounts as a prepayment for income tax can partly resolve this difficulty, but any ex post reconciliation mechanism should not impose an unduly high administrative burden on P2P businesses, especially as these activities could be sensitive to high taxes or high compliance costs.

The tax treatment of the P2P economy will ultimately depend on each government's preferences and capacity, and will likely vary by country. Some governments may wish to minimize tax policy differences between P2P sellers and traditional businesses. Others may instead see the rise of the $\mathrm{P} 2 \mathrm{P}$ economy as positive and choose to provide tax incentives to encourage it. What is clear is that while the P2P economy has potentially exacerbated the administrative and revenue mobilization challenges associated with small business taxation, the technology behind P2P platforms presents a valuable opportunity to eventually solve them. 


\section{Box 1. Peer-to-Peer Activities in DeVeloping Economies}

The level of economic development can alter how P2P activities evolve and the impact they will have on an economy. While there may be a displacement effect in more advanced economies, the informal provision of personal services (such as taxi drivers, plumbers, and cleaners) is typically widespread in emerging market and developing countries. In this context, intermediating P2P activities over digital platforms may allow greater access, better organization, and formalization of previously informal economic activity.

Use of these collaborative approaches is already widespread in countries such as Colombia, Kenya, Mexico, and South Africa, both by foreign and locally developed platforms. The P2P economy can increase sources of income quickly and effectively, promote entrepreneurial spirit, and encourage innovations to address constraints faced by these economies, such as ride-sharing as a means to alleviate strains on or substitute for public transportation.

The P2P business model is a unique opportunity to help overcome unreliable governance, weak property rights, and binding capital constraints common in emerging market and developing countries. These factors preclude effective regulation or the development of natural monopolies in markets-notably services - where information asymmetry is a serious problem. The decentralized, crowd-based ratings technology that underpins P2P businesses helps mitigate the need for large capital investment or detailed regulation and good governance. It lowers the capital and regulatory bar for the sort of search and match that is required for an effective services industry to flourish. Given that such countries lack the institutional means to overcome such information problems, it is those sectors that lack the ability to have well-functioning regulation or large reputable companies that can benefit most from technology that overcomes information failures in services.

Yet, despite the ingenuity of P2P technology in helping smaller-scale enterprises overcome financial and informational constraints on the supply side, P2P businesses face other demand-side obstacles in many emerging market and developing countries. Biswas, Pahwa, and Sheth (2015) and the Inter-American Development Bank (2016) report on the P2P economy in India and Latin America, respectively, listing various factors that limit its uptake. These include a lack of knowledge and general distrust of these new collaborative business models by customers, and underdeveloped financial mechanisms - for example, secure payments facilities and insurance. Smartphone penetration can also be an important limiting factor.

Low and concentrated asset ownership in emerging market and developing countries means that the emergence of P2P services that rely on a large capital component could also be limited. The concentration of assets in a small part of the population could also have implications for the distribution of benefits from any sharing activities. Of course, the P2P economy has demonstrated its adaptability in overcoming such inequality in the case of ride-sharing. For example, drivers in South Africa can use a platform (DriverSelect) to identify available cars that are available for rent for use as a taxi, while in other parts of Africa, some P2P businesses are helping drivers finance the purchase of vehicles. Nevertheless, P2P businesses that are labor-intensive are likely to be more successful in countries with large pool of decentralized and underutilized pools of low-skilled labor and where demand for services from tech-savvy urban middle classes is strong. 


\section{Box 2. Current Tax Treatment of P2P Businesses}

\section{Direct taxes}

P2P sellers worldwide typically register as self-employed businesses and are responsible for selfreporting their income and tax liability to the tax authorities. However, given the irregularity of engagement and small scale of many P2P sellers, they might not always be deemed to be conducting business or commercial activity, removing any legal obligation for P2P sellers to report their income to tax authorities. In Australia, for example, activities deemed a hobby (determined by tests on the activity's intention, frequency, and organization) do not carry any tax or reporting obligations, removing small amounts of casual income from the tax net. Moreover, the resale of second-hand personal items on online marketplace platforms will also typically not be taxable since they are usually sold at a loss. However, many countries, including the United States and Canada, are stricter and require reporting of all $\mathrm{P} 2 \mathrm{P}$ income to the tax authorities.

Income exemptions may also apply. For example, for rental income, the U.S. tax authorities allow homeowners to rent out their homes for up to 14 days without having to pay tax on the income. The United Kingdom provides "rent-a-room” relief of up to $£ 7,500$ for owner-occupiers or tenants who let out furnished accommodation to a lodger in their home. In April, two new tax allowances for property and trading income targeted at the digital and sharing economy were also introduced. These allowances remove tax reporting and payment obligations where an individual's trading or property income for the tax year before expenses does not exceed $£ 1,000$. Individuals with incomes above that amount can also opt to deduct the allowance instead of their actual business expenses.

In calculating their tax liabilities, P2P sellers can make tax deductions from their income like any self-employed business. In most countries, deductible items include bringing-to-market costs (cleaning fees, insurance), operating costs such as gasoline, as well as financing costs and capital depreciation. Some countries offer specific deductions depending on the sector. For example, if a car is used for both business and personal purposes in the United States, the taxpayer must apportion expenses based on actual mileage and can apply a standard mileage rate ( $\$ 0.54$ per mile beginning 2016) to determine the deduction. For a home used for business, taxpayers can opt to apply a deduction of $\$ 5$ per square foot for up to 300 square feet.

\section{Indirect taxes}

Where such taxes operate, VAT or a GST will apply to the provision of goods and services in the P2P economy. In some VAT/GST systems, certain exemptions could apply to the P2P economy, for example, long-term residential rental income (over one month) on which the tax is not charged.

From an administrative point of view, businesses only need to register for VAT after a certain threshold of gross income is reached. As discussed in the paper, the rationale for a threshold is usually an administrative practicality, based on the distribution of firm size, costs of administering and complying with the VAT, and the empirical observation that a small number of large firms typically account for a large proportion of VAT revenue. The small amounts of income generated by P2P participants would imply that few would be subject to VAT/GST at current thresholds. 
While the question over who is liable for any transaction taxes has been raised by some authorities and would appear to be closely linked to the worker classification debate, India has already taken a proactive approach. In its 2015 Finance Act, the government introduced provisions under which the platform is liable and therefore required to discharge the tax on services provided by the sellers. However, issues remain including how sellers can claim credits against this liability.

\section{Other taxes}

Some countries apply sector-specific taxes which would extend to P2P business operating in the sector. P2P platforms are moving at different speeds in establishing payment of such taxes. Taxes applicable to hotel guests now extend to users in the P2P accommodation-rental sector and the largest platform, Airbnb, now collects and remits in certain U.S. states.

In most countries, the operation of taxis and private hire vehicles involves the regular payment of license fees. However, in the ride-sharing sector, while the service is most comparable to the taxi sector, the license fees applicable to traditional taxi drivers do not apply. In New York, where taxi drivers must buy a medallion to operate a taxi, the price has fluctuated between about $\$ 500,000$ to over $\$ 1$ million over the last five years. However, some US states have introduced taxes targeted at the ride-sharing sector. For example, in 2016, Massachusetts introduced a $\$ 0.20$ tax on every trip ordered through ride-hailing services earmarked for spending on the traditional taxi sector. In Washington D.C., rides to and from the airport using ride-sharing platforms now incur a $\$ 4$ fee which will be remitted to the airports authority.

\section{Table 2.1. Selected Recent International Legislative Changes Relating to P2P Businesses (2015-17)}

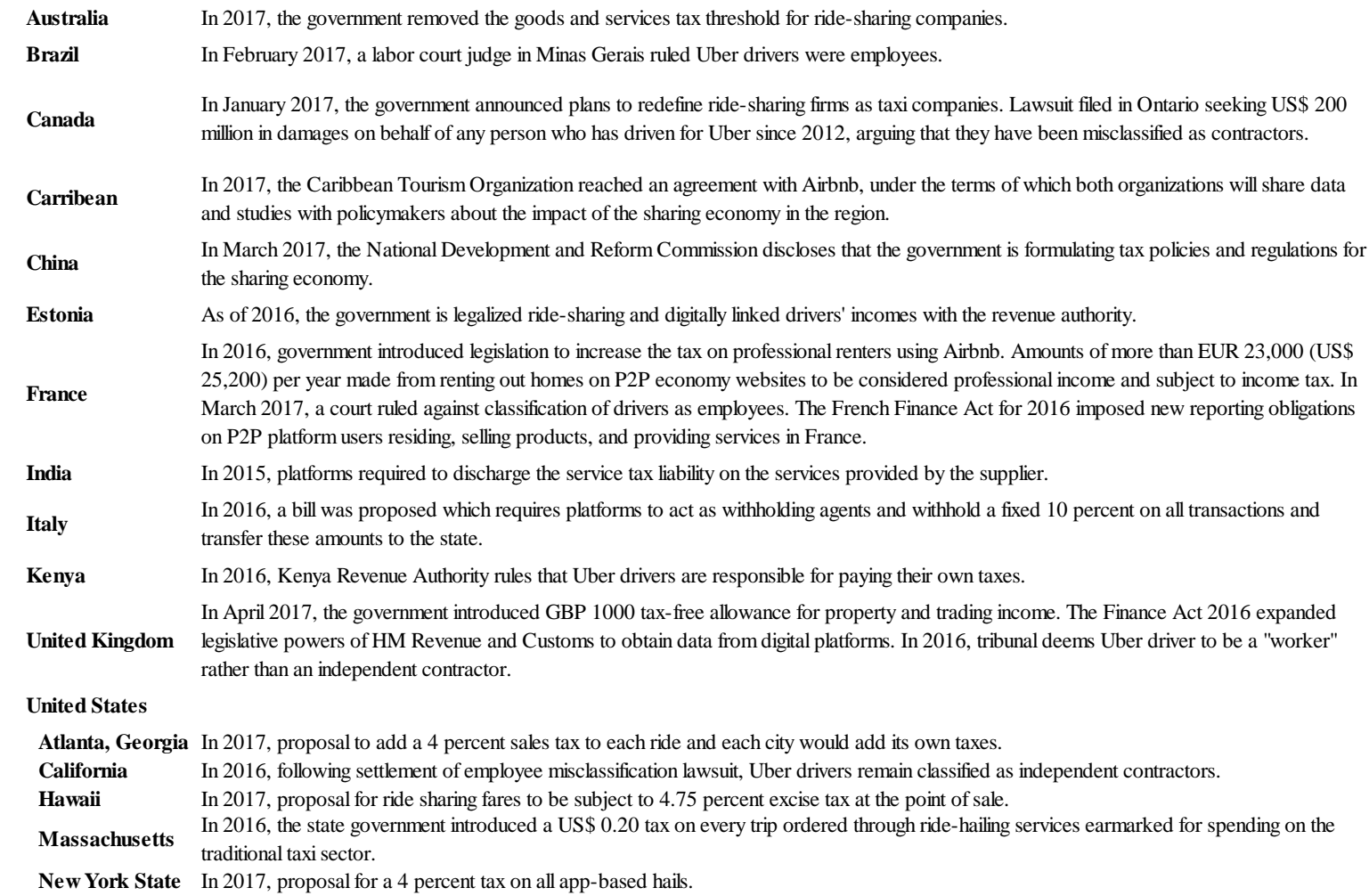




\section{References}

Armstrong, Mark. 2006. "Competition in Two-Sided Markets.” RAND Journal of Economics 37 (3): 668-91.

Atkinson, Anthony B., and Joseph. E. Stiglitz. 1976. “The Design of Tax Structure: Direct versus Indirect Taxation.” Journal of Public Economics 6 (1-2): 55-75.

Benjaafar, Saif, Guangwen Kong, Xiang Li, and Costas Courcoubetis. 2015. "Peer-to-Peer Product Sharing: Implications for Ownership, Usage and Social Welfare in the Sharing Economy.” Unpublished.

Bernhardt, Anne. 2014. "Labor Standards and the Reorganization of Work: Gaps in Data and Research.” IRLE Working Paper No. 100-14, UC Berkeley: Institute for Research on Labor and Employment, Berkley, CA.

Biswas, Ranjan, Ankur Pahwa and Milan Sheth. 2015. "The Rise of the Sharing Economy: The Indian Landscape.” Ernst and Young LLP, London.

Bolt, Wilko, and Alexander F. Tieman. 2008. "Heavily skewed pricing in two-sided markets.” International Journal of Industrial Organization 26: 1250-1255.

Bourreau, Marc, Bernard Caillaud, and Romain De Nijs. 2017. "Digital Platforms, Advertising and Taxation.” Journal of Public Economic Theory, forthcoming.

Brinkley, Ian. 2013. "Flexibility or Insecurity? Exploring the Rise in Zero Hours Contracts." The Work Foundation, Lancaster University, United Kingdom.

Caillaud, Bernard and Bruno Jullien. 2003. “Chicken \& Egg: Competition Among Intermediation Service Providers.” RAND Journal of Economics 34: 309-28.

Chamley, Christophe. 1986. “Optimal Taxation of Capital Income in General Equilibrium with Infinite Lives.” Econometrica 54 (3): 607-22.

Coase, Ronald H. 1937. “The Nature of the Firm.” Economica, New Series 4 (16): 386-405.

Cohen, Peter, Robert Hahn, Jonathan Hall, Steven Levitt, and Robert Metcalfe. 2016. "Using Big Data to Estimate Consumer Surplus: The Case of Uber.” NBER Working Paper No. 22627, National Bureau of Economic Research, Cambridge, MA.

Cullen, Zoë B., and Chiara Farronato. 2016. “Outsourcing Tasks Online: Matching Supply and Demand on Peer-to-Peer Internet Platforms.” Unpublished.

Dabla-Norris, Era, Florian Misch, Duncan Cleary, and Munawer Khwaja. 2017. “Tax Administration and Firm Performance: New Data and Evidence for Emerging Market and Developing Economies.” IMF Working Paper No. 17/95, International Monetary Fund, Washington, DC. 
Department for Business, Energy \& Industrial Strategy. 2017. "Good work: the Taylor review of modern working practices.” London.

Edelman, Benjamin G., and Damien Geradin. 2016., "Efficiencies and Regulatory Shortcuts: How Should We Regulate Companies like Airbnb and Uber?” Stanford Technology Law Review 19 (3): 293-328.

Ellison, Glenn, and Drew Fudenberg. 2003. “Knife-Edge or Plateau: When Do Market Models Tip?” Quarterly Journal of Economics 118 (4): 1249-78.

European Commission. 2017. "Establishing a European Pillar of Social Rights.” Commission Staff Working Document Accompanying the Communication from the Commission to the European Parliament, The Council, The European and Social Committee, and the Committee of the Regions, Brussels.

Evans, David S. 2003. “The Antitrust Economics of Two-Sided Markets.” Yale Journal of Regulation 20: 325-81.

Farrell, Diana, and Fiona Greig. 2016a. "Paychecks, Paydays, and the Online Platform Economy: Big Data on Income Volatility.” J.P. Morgan Chase Institute, New York.

—. 2016b. “The Online Platform Economy: Has Growth Peaked?” J.P. Morgan Chase Institute, New York.

Farronato, Chiara, and Andrey Fradkin. 2016. "Market Structure with the Entry of Peer-toPeer Platforms: The Case of Hotels and Airbnb.” Unpublished.

Fraiberger, Samuel P., and Arun Sundararajan. 2015. "Peer-to-Peer Rental Markets in the Sharing Economy.” NYU Stern School of Business Research Paper.

Goudin, Pierre. 2016. “The Cost of Non-Europe in the Sharing Economy: Economic, Social and Legal Challenges and Opportunities.” Study from the European Added Value Unit, European Parliamentary Research Service, Brussels.

Hall, Jonathan V. and Alan B. Krueger. 2015. “An Analysis of the Labor Market for Uber’s Driver-Partners in the United States.” NBER Working Paper 22843, National Bureau of Economic Research, Cambridge, MA.

Hathaway, Ian, and Mark Muro. 2013. “Tracking the Gig Economy: New Numbers.” Brookings Institution, Washington, DC. https://www.brookings.edu/research/trackingthe-gig-economy-new-numbers/

Horton, John J. and Richard J. Zeckhauser. 2016. “Owning, Using and Renting: Some Simple Economics of the 'Sharing Economy'.” NBER Working Paper 22029, National Bureau of Economic Research, Cambridge, MAMassachusetts.

Inter-American Development Bank. 2016. The Sharing Economy in Latin America. School of Business Enterprise Institute (IE), Madrid. 
International Monetary Fund (IMF). 2015. "Current Challenges in Revenue Mobilization: Improving Tax Compliance.” International Monetary Fund, Washington, DC.

Judd, Kenneth L. 1985. "Redistributive Taxation in a Simple Perfect Foresight Model.” Journal of Public Economics 28 (1): 59-83.

Kanbur, Ravi, and Michael Keen. 2014. "Thresholds, Informality and Partitions of Compliance.” International Tax and Public Finance 21 (4): 536-59.

Keen, Michael, and Jack Mintz. 2004. "The Optimal Threshold for a Value-Added Tax.” Journal of Public Economics 88 (3-4): 559-76

Kind, Hans J., Marko Koethenbuerger, and Guttorm Schjelderup. 2008. "Efficiency Enhancing Taxation in Two-Sided Markets.” Journal of Public Economics 92 (5-6): 1,531-39.

_ 2010. “Tax Responses in Platform Industries.” Oxford Economic Papers 62 (4): 764-83.

Manyika, James, Susan Lund, Jacques Bughin, Kelsey Robinson, Jan Mischke, and Deepa Mahajan. 2016. "Independent Work: Choice, Necessity, and the Gig Economy." McKinsey Global Institute, New York.

Martin , Elliot, Susan A. Shaheen, and Jeffrey Lidicker,. 2010,. "Impact of Carsharing on Household Vehicle Holdings: Results from North American Shared-Use Vehicle Survey.” Transportation Research Record: Journal of the Transportation Research Board, No. 2143, Transportation Research Board of the National Academies, Washington, DC.

Neeser, David. 2015. "Does Airbnb Hurt Hotel Business: Evidence from the Nordic Countries.” Unpublished.

Oei, Shu-Yei, and Diane M. Ring. 2016. “Can Sharing Be Taxed?” Washington University Law Review 93 (4).

Office of National Statistics. 2016. "The Feasibility of Measuring the Sharing Economy.” Article from the Office of National Statistics, London. https://www.ons.gov.uk/economy/economicoutputandproductivity/output/articles/thefeasi bilityofmeasuringthesharingeconomy/2016-04-05.

Robertson, Dennis. H. 1923. The Control of Industry. Hitchin, United Kingdom: Nisbet \& Co.

Rochet, Jean-Claude, and Jean Tirole. 2003. "Platform Competition in Two-Sided Markets." Journal of the European Economic Association 1 (4): 990-1024.

Rosenblatt, Alex, and Luke Stark. 2016. "Algorithmic Labor and Information Asymmetries: A Case Study of Uber’s Drivers.” International Journal of Communication 10 (2016): 3758-84. 
Rysman, Marc. 2009. “The Economics of Two-Sided Markets.” Journal of Economic Perspectives 23 (3): 125-43.

Schor, Juliet B., and Connor J. Fitzmaurice. 2015. "Collaborating and Connecting: The Emergence of the Sharing Economy.” In Handbook on Research on Sustainable Consumption, edited by Lucia Reisch and John Thogersen, Cheltenham, UK: Edward Elgar.

Smith, Aaron. 2016. "Shared, Collaborative and On Demand: The New Digital Economy.” Pew Research Center, Washington, DC.

Thomas, Kathleen D. 2017. “Taxing the Gig Economy.” UNC Legal Studies Research Paper No. 2894394, University of North Carolina, School of Law, Chapel Hill, North Carolina.

Vaughan, Robert, and Raphael Daverio. 2016. "Assessing the Size and Presence of the Collaborative Economy in Europe.” PricewaterhouseCoopers, London.

Wallsten, Scott. 2015. "The Competitive Effects of the Sharing Economy: How is Uber Changing Taxis?” Technology Policy Institute, Washington, DC.

Williamson, Oliver E. 1981. "The Economics of Organization: The Transaction Cost Approach.” American Journal of Sociology 87 (3): 548-77.

Zervas, Georgios, Davide Proserpio, and John W. Byers. 2017. "The Rise of the Sharing Economy: Estimating the Impact of Airbnb on the Hotel Industry.” Journal of Marketing Research, In-Press. 